\title{
7 Increasing the Forces of Life: Biopolitics, Capitalism and Time in Marx and Foucault
}

It is no longer the worker who employs the means of production, but the means of production which employ the worker. Instead of being consumed by him as material elements of his productive activity, they consume him as the ferment necessary to their own life-process, and the life-process of capital consists solely in its own motion as self-valorizing value.

(Marx 1990, 425)

Since the classical age the West has undergone a profound transformation of these mechanisms of power. 'Deduction' has tended to be no longer the major form of power but merely one element among others, working to incite, reinforce, control, monitor, optimize, and organize the forces under it: a power bent on generating forces, making them grow, and ordering them, rather than one dedicated to impeding them, making them submit, or destroying them.

(Foucault 1980, 136)

\subsection{Missing the Link: Biopolitics and Capitalism}

At the beginning of the $21^{\text {st }}$ century, the biofication of terms finally entered the field of economics. Compounds such as biotechnology, biomedicine, bioethics, biolaw and, to a lesser degree, biopolitics, had already taken off in the 1980 s and 90s, whereas notions of bioeconomy, biovalue, and biocapital did not proliferate until the early 2000s. Like the term biopolitics, they are being used in very disparate ways, seeking either to promote or to critique the subject they are referring to. Those who use them in a critical way customarily refer in one way or other to the concepts of biopolitics and biopower as coined 
by Michel Foucault. ${ }^{1}$ Even within this tradition, however, the relationship between biopower and biopolitics on one hand and (bio-)value, (bio-)capital and (bio-)capitalism on the other is still relatively unclear. As Ute Tellmann $(2017,69)$ rightly notes, the nexus between liberal economics and biopolitics is often assumed but seldom explored. This holds all the more true for the relation between biopolitics and capitalism. Although there is much mention of biopolitics and liberalism, biopolitics and liberal governmentality, biopolitics and biovalue, or biopolitics and biocapital in the literature, the focus is rarely on the relationship between biopolitics and capitalism. The concept of capitalism almost never figures in this literature, and when it does, it tends to be equated either with liberalism or with a particular segment of the economy that makes use of the biosciences and biotechnology. We can thus distinguish two main approaches to relating issues of biopolitics and capitalism in the Foucauldian tradition, which I will term the 'technologycentred approach' and the 'government-centred approach'.

\subsection{Biopolitics as Biotechnology}

I borrow here the concept of a technology-centred approach from Lars Thorup Larsen (2007), denoting a line of work on the relationship between biopolitics and economics that focuses not so much on government but on bioscience and biotechnology. The concepts of bioeconomy, biovalue, bioproperty and biocapital here denote either a particular sector or era, or both, of $20^{\text {th }} / 21^{\text {st }}$-century economics, namely one capitalizing on the potential of life processes, from the molecular level to the human body, based on advances in technoscientific

Unfortunately, Foucault himself never clarified the relationship between the two concepts. Sometimes, he seems to use them synonymously; then again, biopolitics appears to denote a subset of ways through which biopower is exercised. The confusion is further exacerbated by the popularity of the term 'biopolitics' since about the turn of the millennium and by the fact that Foucauldian and non-Foucauldian uses often intermingle in the literature. While biopolitics is the more widespread term, biopower, in Foucault, is arguably the more fundamental one. As a counterpart to sovereign power, biopower denotes a new, epochal form of power that pervades different strata, spheres and dimensions of modern society. Since this is actually the theoretical level this chapter is aiming at, biopower would thus in many cases be the more appropriate term. Since, however, biopolitics is the more common one in the literature, I will for pragmatic reasons generally use that term here. 
knowledge production (Helmreich 2008). The focus here is on studying the political economy of the biotech industry, including the disentanglement and valorization of biological objects or processes and the development of individual business models and investment strategies. On the general level, one can add to these the formation of markets, research and development strategies, economic discourses, and visions and imaginaries-as well as, importantly, the transformation of economic structures in interaction with biomedical and biotechnological knowledge production (Cooper 2008; Rose 2007; Sunder Rajan 2006; Waldby 2008; 2009; Waldby and Cooper 2010). The concepts of capital and capitalism come into play when and insofar as the valorization of bodies, life processes, biosciences and biotechnologies are analyzed as situated within a capitalist economy governed by capitalist principles of competition and profit-seeking and, though it is more rarely addressed in the literature, exploitation. For technology-centred approaches, biopolitics concerns the ways in which life processes are made accessible, mobilized and enrolled in order to utilize their vital potential (Waldby and Cooper 2008, 68). Contemporary biopolitics, in this sense, tends to coincide with biotechnology-based ways of valorizing vitality. Thus, technology-centred approaches have drawn attention to the intricate ways in which bioscientific knowledge production, biotechnology, and bioeconomic valorization strategies mutually shape and reinforce each other in late capitalism, accompanied and to some extent reinforced by the generation of new forms of the individual and collective identities, social relations, networks and communities that Rabinow (1996) dubbed 'biosocialities'. ${ }^{2}$ Yet biopolitics and capitalism come into view only in conjunction with biotechnology or biomedicine; the focus is on industries, markets and business strategies organized around biotechnology or biomedicine, that is, on industries, markets and the quest to harness the potential of life processes in the body, body parts or body materials through recent advances in genetics, biochemistry or reproductive medicine. Thus, in the last instance, it is the advent of reproductive medicine and the new genetics that marks the emergence of biocapital. While this strand of research has greatly advanced our understanding of the interpenetration between knowledge production in the life sciences, the formation of new markets and industries, state policies

2 For an overview on the discussion concerning the relation between the biosciences, biosociality and the economy, see Cibbon and Novas 2007; for a critique of implicitly techno-determinist assumptions underlying the concept of biosociality see Gerhards 2020, 57. 
and institutional arrangements as well as identity and community formation (Gibbon and Novas 2007, 13), it highlights only a particular segment of biopolitics and capitalism and does not discuss the relationship between the two on a conceptual level. A problem arises when biopolitics is conceptually reduced to political or economic activities organized around biotechnology. Despite assertions to the contrary, this stance bears an implicit tendency towards technological determinism if and when it takes late- $20^{\text {th }}$ century advances in genetics, biotechnology and reproductive medicine to be the origin and the driving force behind contemporary biopolitics and its interpenetration with the economy. Such a stance also leaves open two questions: whether and how these advances themselves may be shaped and driven by a logic of biopolitics and how this relates to the logic of capitalism. Relatedly, a technology-centred conception of biopolitics tends to overlook or play down biopolitical strategies not necessarily organized around the life sciences but operating through various forms of social, employment, family or immigration policies, through urban planning, social work, birth control campaigns and the like on state, sub-state and global levels, thus ignoring much of what Foucault termed the biopolitics of the population. While Nikolas Rose in 2007 still assumed, at least for late modern liberalism, that state-led interventions on the level of the population were a matter of the past and that biopolitics had become individualized and molecularized, the return of the camps, the selective closing of borders, the rehabilitation of population policy (Schultz 2019) and openly eugenic discourses (Wehling 2010; 2019) leave no doubt that this is no longer true-if it ever was. A technology-centred concept of biopolitics falls short of capturing these persistent yet ever-changing practices, discourses and social technologies of selectively managing the size, structure and qualities of human groups and populations.

\subsection{Biopolitics as Self-Government}

Government-centred approaches, by contrast, do not focus on matters of science and technology but rather on the relationship between biopolitics, liberalism and technologies of government. Liberalism in this literature, is basically conceived as a political rationality operating through ideas, technologies and mechanisms of governing at a distance (Dean 2002; Larsen 2007; Lemke, Krasmann et al. 2000; Tellmann 2017). It enrols individuals, families, neighbourhoods and other collectivities in programmes of self-government 
and self-improvement, particularly with regard to health, fitness, sexuality, procreation and other aspects of bodily life. It thereby shifts responsibility for public health, wellbeing and security from the state to individuals, families, groups, neighbourhoods or other collectivities. Biopolitics, in this context, comes as a set of mechanisms for promoting self-government and selfimprovement, or, as its inverse, a set of mechanisms for disciplining those deemed incapable thereof. Thus, biopolitics and liberalism ultimately converge on the terrain of disciplining and responsibilizing individuals. Biopolitics, in short, operates as an instrument of (neo-)liberal government. From this perspective, however, it remains somewhat unclear what, if anything, is the added value of concepts such as biopower and biopolitics. If biopower and biopolitics basically denote technologies of discipline and responsibilization, then why not retain these concepts? What, in short, is the 'bio' in biopolitics, and why does it matter?

More recently, Ute Tellmann has suggested approaching this question on a more systematic level. The Foucauldian tradition, Tellmann holds, tends to assume that the biopolitics of the population coincides with a liberal economic governmentality, thus establishing a metonymic nexus between population, biopolitics and economic government that is, however, never submitted to closer theoretical examination (Tellmann 2011, 61). She suggests investigating this nexus by taking a closer look at the work of Thomas R. Malthus. Going back to Malthus, she argues, allows us to reconstruct the missing link between biopolitics and liberal economics that is constituted by the connection between population and scarcity (Tellmann 2017). The notion of scarcity, she holds, assumes a key position in modern economy, defining its boundaries both in terms of economic discourse and in terms of a separate sphere in society. After all, it is reference to the problem of scarcity that sets the economic sphere apart from the sphere of politics (Tellmann 2017, 204). Starting from Malthus, according to Tellmann, we can reconstruct the biopolitical origins of modern economics founded on the inherently racist and colonialist distinction of civilized human life and savage life. The key to understanding this nexus, she argues, is the third element in the connection: time. While savage life is caught up in a timeless present, unable to think ahead, consuming and procreating excessively through times of abundance without providing for the future, civilized life breaks the cycle of abundance and scarcity, resists the temptations of excessive consumption and procreation, and allows for economic progress to take place. Thus, in Malthus, savage life and its lack of futurity are responsible for scarcity and misery among the whole of the 
population. Thus, for Tellmann, the missing theoretical link between biopolitics and capitalism is to be found in the nexus between scarcity and futurity and this notion of the population. Biopolitics basically denotes the difference between savage and civilized life, coinciding with a difference between a timeless present on one hand and the quest for a better future on the other. It thus also marks a corresponding historical leap. In that sense, biopolitics coincides with the birth of modern liberal economy; it disciplines uncontrolled needs and desires for the sake of eventual fulfilment in the future, thus substituting immediacy for futurity. By doing so, biopolitics constitutively implies a hierarchy of human life, a value differential between savage, present-oriented and civilized, future-oriented life.

Tellmann draws attention to two important features of biopolitics to which I will return later: the relationships among the modern market economy, biopolitics and future-oriented temporality, as well as the value differential ascribed to different forms of human life. However, concerning the issue of biopolitics and capitalism, a few questions remain open. In particular, the focus here is on the relation between biopolitics and liberalism, not biopolitics and capitalism; Tellmann does not use the term capitalism. The meaning of liberalism, however, remains somewhat vague, oscillating between liberal political rationality, market economy and classical political economic discourse. Unlike the concept of capitalism, it does not denote a particular form of society with a particular mode of production and particular forms of social relations. Further, Malthus does not have much to say about biopolitics after a modern liberal economy has been established. Is biopolitics still taking place? Has savage life been replaced by civilized life once and for all, so that the biopolitical makes only a single appearance in history? Or does savage life, rather, form a subterraneous layer of human life that continues to threaten the liberal order? In that case, the role of biopolitics in liberalism would be that of a permanent force of repression. Both assumptions-biopolitics as a singular event and biopolitics as a permanent force of repression-lack, I would argue, the peculiar, distinctively modern features of biopolitics and its relation to capitalism. While I agree with Tellmann that both biopolitics and capitalism are inherently future-oriented, I would object that the future toward which they are oriented is not one in which needs are met and scarcity is overcome. Concerning the connection between capitalism and biopolitics, I posit that there is more to learn from Marx than from Malthus: namely that what drives the dynamics of capitalism is not the problem of scarcity but the logic of accumulation. 
In sum, government-centred approaches tend to reduce capitalism to liberalism while technology-centred approaches tend to reduce biopolitics to biotechnology. None addresses the relationship between biopolitics and capitalism more specifically or on both a theoretical and conceptual level. In order to do so, I suggest a return to Foucault and Marx and their respective conceptualizations of biopolitics and capitalism. I argue that, notwithstanding the obvious differences, there are some remarkable convergences between their analyses of biopower/biopolitics and capitalism, and that these concern above all the investigation of power, life and time under conditions of modernity and the nexus between them. As regards power, both Marx and Foucault study first and foremost the productive face of power, its productive way of operating. This does not mean that power for them is not repressive, but that its repressivity becomes intelligible only through studying its productivity. Further, for both Marx and Foucault, life is a key resource for this type of power. In fact, life is a genuinely modern resource in that it is the resource that can be simultaneously used/exploited and improved/increased. Life is the subject, the resource and the product of modern productive power. And finally, for both Marx and Foucault, time is key. Time in modernity, or rather temporality, is the mode of existence of (bio-)power and capital. Both (bio-)power and capital share a performative ontology in that they exist only in action, only when and insofar as they are being performed. Moreover, as I will show, capital and biopower/biopolitics share an inbuilt temporality that is not sufficiently captured by the concept of futurity. This temporal structure is characterized by an ongoing, unlimited process of ever-increasing productivity, thus directed at the future but not at future fulfilment. Instead, it is a permanent, unlimited process of maximizing and optimizing that cannot possibly come to a meaningful end.

\subsection{Power and Productivity}

Marx' Critique of Political Economy and Foucault's work on biopolitics belong to the highest ranks of social theory ${ }^{3}$, seeking to capture the epochal features of modern sociality. Neither is content to study merely a single segment of society: Marx does not study 'the economy' but the ensemble of social relations 
in "societies in which the capitalist mode of production prevails" (Marx 1990, 125). And biopolitics in Foucault does not denote a particular policy domain, defined e.g. by reference to medicine or biology (Braun and Gerhards 2019; Wehling 2008), but a historically specific mode of social integration, one that promises to integrate the individual into the social order in a way that benefits both at the same time (Braun and Gerhards 2019; Foucault 2000a; 1994a). ${ }^{4}$

For both Marx and Foucault, productivity, not repression or deprivation, is key to understanding power in the modern world. In their view, it is pointless to battle the forces of repression without tackling the forms through which social relations, social thought and the ways of being a social agent are being shaped and created. This does not mean that repression, extraction, misery and deprivation are insignificant in their analyses; they do not, however, hold the key to understanding and ultimately overcoming the dominant forms of social thought and practice in the present. The key is how we produce and reproduce these forms and how they are imbued with power.

As is well known, the concept of power that Foucault introduces in The Will to Knowledge goes beyond the preoccupation with repression, misery and deprivation, highlighting, rather, the productive dimensions of power. Power, he insists, is not just the lid that holds down our boiling-up desires and unduly constrains the forces of sexual and political liberation. Rather, it is a variable constellation of forces within which subjectivities are forming and being formed. For Foucault, the belief that sexual liberation, truth telling and selfexposure will free us from power and allow us to flourish both personally and politically, is itself a historically specific effect of power. Instead, he insists, power produces truth, sexuality, subjects, and the relations between them, and it is precisely the question of how they are produced that concerns him. As long as we stay focused on the negative operations of power-such as the

Jacques Bidet (2016) also reads Foucault as a social theorist, placing him on a par with Marx in that both, he argues, highlight two equally constitutive poles of instrumental reason that dominate the modern social order: capital and organisation. Both rely on respective privileges that allow the dominant class to exercise power, namely the privilege of property and the privilege of elite competencies. Power is here essentially conceived as power over: managerial power over workers, medical power over the ill, university power over students (Bidet 2016, 96). While I agree with Bidet that both Marx and Foucault theorize the modern social order in terms of instrumental reason, I will not highlight the more Weberian conception of "power over" in Foucault but rather seek to bring to the fore the shared logic of capital and biopolitics, their common, inbuilt dynamics towards increasing human productivity. 
questions of how truth is being distorted or obscured, how sexuality is being repressed, and how we all are being alienated from our true selves-as long as we focus on this, Foucault argues, we are trapped in a humanist mindset, tying ourselves to some hidden essence, some lost origins that prevent us from truly trying something new. Rather than searching for the truth lost, Foucault suggests, there is more to gain from understanding how truth is being produced. Only if we realize that the alleged nature of man, the essence of the state, or the subject are nothing but historically contingent ways of thinking and acting, will it be possible to do things differently, to live differently and possibly feel differently. Hence, Foucault assumes, focusing on the productive operations of power will potentially give us more freedom to not merely bemoan repression but think and do things differently.

Now, on the one hand, the shift from a 'negative' towards a 'positive' concept of power is clearly deployed against Freudo-Marxism and its preoccupation with sexual repression respectively liberation. Foucault consistently distances himself from what he sees as totalizing approaches, approaches claiming to deduce the effects of social and political power relations from certain economic or political categories, for instance, seeking to deduce "the status of the mad, the sick, children, delinquents, and so on, in our kind of society" from the category of the state, or the category of the state from the category of the commodity and so forth. "[T]hen I reply: Yes, of course, I am determined to refrain from that kind of analysis" (Foucault 2008, 78). Instead, he suggests to approach "our kind of society" through a critical history of the present that would focus on the genealogy of practices and problematizations and the struggles around them.

On the other hand, however, this shift was clearly inspired by Marx:

I will make a presumptuous comparison. What did Marx do when in his analysis of capital he came across the problem of the worker's misery? He refused the customary explanation which regarded this misery as the effect of a naturally rare cause or of a concerted theft. And he said substantially: given what capitalist production is, in its fundamental laws, it cannot help but cause misery. Capitalism's raison d'être is not to starve the workers but it cannot develop without starving them. Marx replaced the denunciation of theft by the analysis of production. Other things being equal, that is approximately what I wanted to say. It is not a matter of denying sexual misery, nor is it however one of explaining it negatively by a repression. The entire prob- 
lem is to grasp the positive mechanism which, producing sexuality in this or that fashion, results in misery. (Foucault 1977, 153f.)

In a word, Marx developed a positive, non-juridical concept of power that serves as a model for Foucault. In a less well-known text dating back to a 1976 talk at the University of Bahia, Foucault explicitly refers to Marx' Critique of Political Economy as assembling the elements constituting this specifically new, modern type of power. What are these elements? First, Foucault insists, there is not one power for Marx, but different types of domination or subjugation that each have emerged from specific local and historical contexts and show specific technologies and mechanisms. He mentions the workshop, the army and the slave plantation to underline the scope of variety. "Society is an archipelago of different powers" (Foucault 2012[1976], 4). Second, for Marx, according to Foucault, the formation of sovereignty does not come first and society second, as the juridical conceptions by Grotius, Pufendorf and the contract theorists would have it. The reverse is true: The regional powers come first and state power second. Third, and most importantly, these regional powers do not primarily operate by means of restriction and prohibition; they do not primarily operate juridically: "The original, essential and permanent function of these local and regional powers is, in reality, being producers of the efficiency and skill of the producers of a product" (Foucault 2012, 5).

Note that it is not primarily the product that is being produced here but "the efficiency and skill of the producer". In Marxian terms, this would be the productivity of living labor. In Foucauldian terms, productive power is biopower in that it turns the body and the population into a resource whose vital forces are to be increased and enhanced. Both Marx and Foucault, thus, are concerned with a type of power directed at shaping, increasing and enhancing the vital forces of the human, at maximizing human skills, capacities, efficiency and functionality. Put differently, what distinguishes modern, productive power from other types of power is that its mechanisms and technologies are directed at shaping, enhancing, optimizing and maximizing the productive life forces of the human. Moreover, for both Marx and Foucault, technology is crucial to this form of power, although their attention is on different types of technology: big machinery in Marx and social and political technologies in Foucault. Still, technology is of the essence as it is through technology, or technologies, that human skills, capacities, efficiency and functionality are increased and improved. Therefore, these technologies themselves become the subject of constant optimization; they are constantly 
being refined, improved, made more efficient. This would be the fourth characteristic element of productive power that Foucault finds in Marx:

these mechanisms of power, these procedures of power, it's necessary to regard them as techniques, which is to say as procedures that were invented, perfected, that were unceasingly developed. There is a veritable technology of power, or better still, of powers, which have their own history. Here, once again, we can easily find between the lines of the second volume of Capital an analysis, or at least the outline of an analysis, which would be the history of the technology of power, such as it was exercised in the workhouses and factories. (Foucault 2012, 6)

Hence, Foucault says: Technologies of discipline precede the historical formation of capitalism; capitalism is not the origin of these technologies of power; rather, it is the effect of their proliferation and intensification at different sites and in different settings. The workhouse comes first; capitalism comes second. And although technologies of discipline and control as developed in the workhouse, but not only there, eventually proved functional for capitalism, the type of power they manifest was not brought into being by capitalism. This might also be the place to note that, in the course of the $20^{\text {th }}$ century, it turned out that biopolitical rationality was not confined to capitalist societies. The prisons, penitentiaries, and psychiatric institutions, not to speak of the camps under Stalinism and in many state socialist regimes, provide ample evidence of that. Moreover, as we saw in Chapter 2 of this book, it was not uncommon for biopolitical rationalities to be linked to welfarist rationalities, as in the case of socialist or social reform movements that promoted eugenic policies as a means to build a functioning welfare state. In short, biopolitics and capitalism share the logic of increasing the forces of life as a means of increasing human productivity and functionality, but that does not mean that this logic is the exclusive property of capitalist society. Rather, we can say that welfarist, socialist and capitalist biopolitics share a modern, productivist rationality that may operate within different economic and political regimes.

To summarize, we have seen that Foucault is not at odds with Marx, but in fact agrees with him regarding the heterogeneous origins, the historicity

Jacques Bidet, however, has noted that Foucault referred erroneously to Volume Two of Capital here and that the editors of the talk repeated this error. In fact, Foucault referred to Marx' historical accounts of factory discipline in the chapter on machinery and large-scale industry in Volume One (Bidet 2016, 22). 
and the distinctively productive nature of modern power. So far, however, the commonalities we have seen concern only the historical accounts presented in Capital, not Marx' more original, distinctive analytical approach, namely form analysis. On the form-analytical level, one would expect more fundamental differences between Marx and Foucault, given that form analysis was in fact Marx' original way of seeking to capture and expose the totality of power relations that characterize capitalist society. To be sure, it is not a homogeneous, monolithic totality with which Marx presents us; it is a fractured, distorted, even hostile totality constituted by inherent antagonisms and contradictions and subject to struggle and contestation, but it is a totality nonetheless, meaning that the critical, historically specific forms characterizing the capitalist mode of production-such as commodity, money, value, wage labor, or capital-are necessarily implicating and co-reproducing each other. While Marx seeks to expose the 'laws' that govern this type of society and the mechanisms that tie these forms to one another, constantly reproducing this 'wrong' form of sociality, Foucault rejects "the inhibiting effect specific to totalitarian theories, or at least [...] all-encompassing and global theories" (Foucault 2003,6 ). He deliberately claims to replace them in favor of what he calls local critique. All-encompassing theories, and he mentions Marxism and psychoanalysis here, may be useful for local critiques if and only if:

...the theoretical unity of their discourse is, so to speak, suspended, or at least cut up, ripped up, torn to shreds, turned inside out, displaced, caricatured, dramatized, theatricalized, and so on. (Foucault 2003, 6)

It is at this point that Foucault parts company with Marx. He does not seek 'laws' that necessarily tie any form to any other, nor does he attempt to capture the totality of any social formation. The new type of theory that may emerge from local critique, he proclaims, "does not need a visa from some common regime to establish its validity" (Foucault 2003, 6). Whether or not Foucault-particularly in his work on biopolitics and biopower-complies with his own stipulations and actually avoids any totalizing move, and whether it is at all possible to articulate critique without theorizing social totality, is debatable (see e.g. Geisler and Struwe 2019). In the following pages, I do not discuss this question on a general level but point out that, notwithstanding these theoretical-political differences, Foucault's conception of power, as manifested in his analysis of biopolitics and biopower, shows remarkable commonalities with Marx' conceptual analysis of value accumulation as the 
essence of capital. To allow these commonalities to emerge, it is necessary to first revisit Marx' analysis of capital accumulation as the heart of capitalism.

\subsection{Enhancing the Forces of Life}

The main focus and the starting point of Capital is, importantly, wealth, not scarcity. More precisely, Marx starts from the form of wealth and wealth production in capitalist society. Hence the much-quoted introductory phrase of Capital:

The wealth of societies in which the capitalist mode of production prevails appears as an 'immense accumulation of commodities'; ${ }^{6}$ the individual commodity appears as its elementary form. (Marx 1990, 125)

Wealth, with its specific form and production, is the subject of analysis in Capital. More precisely, the subject under study is wealth in capitalist society. In the course of analysis, it results that wealth in capitalist society may well appear as an accumulation of commodities; this is not wrong, but it is incomplete. In fact, the specific form of wealth in societies with capitalist mode of production is the accumulation of value, with accumulation not meaning 'a greater amount of' but the process of accumulation. Value, in Capital, is not a thing or a quality, such as color or weight, nor is it a substance. I follow the interpretation of Michael Heinrich (2004) here, who emphasizes that Marx in Capital explicitly abandons the idea that value is created when isolated producers spend private labor-time on the production of a certain use-value, so that from the moment of production, value resides in the labor product. This notion goes back to classical political economy and assumes that value-creation was a universal, ahistorical feature of human labor as such. In Capital, Marx departs from this ahistorical, humanist assumption and demonstrates that value and, consequently, value creation, are features of labor only under the conditions of a fully developed capitalist mode of production. Labor products, according to this reading, do not have value prior to and independent of the act of being exchanged; accordingly, the value of a commodity is not determined by the quantity of labor expended on it. Otherwise, a slow and clumsy worker would automatically generate more value than a swift and skilful one (Marx 1990, 129). Rather, the magnitude of value of commodities 
is determined by the 'socially necessary labor-time' that is required on average to produce "any use-value under the conditions of production normal for a given society and with the average degree of skill and intensity of labor prevalent in that society" (Marx 1990, 129). This, however, cannot be determined in advance, not least because it is subject to constant change. Therefore, Marx argues that value is determined in the act of exchange. In the act of exchange, the producers actively compare the products of their labor, abstracting from the particular content of that labor. "They do this without being aware of it" (Marx 1990, 166f.). ${ }^{7}$ The common parameter according to which commodities are compared to one another is the expenditure of labor-time, that is, abstract labor or labor sans phrase. Value has no existence independent from this act of comparison in and through the act of exchange; the act must be performed for value to exist.

In societies with a capitalist mode of production, commodities are regularly produced for the market, which presupposes a certain level of division of labor, and exchanged against money, meaning that the reproduction of society is critically mediated through exchange. Under these conditions, producers, in and through the act of exchange, do not merely relate the products of their private labor to each other; rather, they relate the fragment of social labor represented in their labor products to the total labor of society (Heinrich $2004,55)$. Value, therefore, is essentially a social relation, a particular form of organizing social life that dominates capitalist society. It assigns certain positions to its members and imposes certain imperatives on them, above all the imperative to sell their labor power if they are owners of nothing but this and to accumulate value if they are owners of means of production.

When the capitalist mode of production is fully developed, Marx argues, and the dominant form of production is production for the market, the logic of the market requires participants to strive for accumulation, for the valorization of value, if they want to maintain their economic existence. Ultimately, therefore, wealth in capitalist societies takes the form of an endless, perpetual, self-propelling process of value accumulation. Accumulation is end-less in that is has no endpoint, no point of sufficiency, no ends in the sense of attainable objectives. It is this uncanny, self-propelling, end-less mode of existence that, for Marx, imbues capital with 'life' and makes it lifelike: 
But capital has only one sole driving force, the drive to valorize itself, to create surplus-value, to make its constant part, the means of production, absorb the greatest possible amount of surplus labour. Capital is dead labour which, vampire-like, lives only by sucking living labour, and lives the more, the more labour it sucks. (Marx 1990, 342)

Capital, for Marx, is feeding on life; it is consuming life in the form of living labor. Under conditions of capitalism, the production process is at the same time a process of consumption-consumption of living labor-and, potentially, of the production of surplus value. Thus, labor is extracted, even wasted, and made productive at the same time. This is possible because living labor's potential to create value is not limited to creating the value of the goods necessary to maintain its existence. Provided that surplus value can be realized on the market, it can be reinvested to further increase the productivity of labor and make some additional profit. Thus, capital does not simply consume and waste labor but rather assimilates it to its own vampire-like form of existence, transforming labor into its own antagonist, capital. As if under a spell, living labor is forced to feed both capital accumulation and an increase in the forces of production.

We can now see how capital accumulation begins to resemble biopolitics, how biopolitics resembles capital as analyzed by Marx, and in what sense Foucault may have taken inspiration from this analysis. Biopolitics, in Foucault, displays the same logic that characterizes the logic of capital accumulation: the logic of a productive type of power that grows and proliferates while exploiting the forces upon which it is feeding. Both capital and biopolitics, in other words, manifest the same historically new and distinctively productive type of power that marks the era of Western modernity. It is a power

...working to incite, reinforce, control, monitor, optimize, and organize the forces under it: a power bent on generating forces, making them grow, and ordering them, rather than one dedicated to impeding them, making them submit, or destroying them. (Foucault 1980, 136)

Biopolitics and biopower, for Foucault, are particularly dominant manifestations of this new, productive type of power that co-emerged with modernity, a type of power geared towards preserving and enhancing human life, its forces, strength and productivity, of "improving and enhancing the functionality of biological human life" (Wehling 2008, 251). 
Yet the potential to increase the life forces and productivity of the individual is limited, not least by human mortality. Increasing human productivity on the level of the population is not limited in the same way. While individual bodies are necessary for the process to proceed, while they may form targets of improvement strategies, while without the existence and functionality of individuals no accumulation or biopolitics could take place, the individual is nothing but a moment within an overarching process that proceeds on the supra-individual level. Biopolitics "is a technology in which bodies are replaced by general biological processes" (Foucault 2003, 249). On these grounds, Foucault points out, an overall policy of improving, maximizing and optimizing the life, fitness and productivity of the population may be compatible with a politics of selection, racism and elimination as executed by the Nazi state (Foucault 2003, 254ff.). In Nazi biopolitics, taking the lives of some-the inferior, the weak, the deficient, unfit or unproductive or racially unworthy-was a mechanism for improving life on the level of the master race:

The more inferior species die out, the more abnormal individuals are eliminated, the fewer degenerates there will be in the species as a whole, and the more I-as species rather than individual — can live, the stronger I will be, the more vigorous I will be. I will be able to proliferate. (Foucault 2003, 255)

Nazi biopolitics also demonstrates that biopolitics is by no means restricted to liberalism. It thereby poses a challenge to government-centred approaches as discussed above. If biopolitics is basically understood as a feature of liberal governmentality, one can either stretch the term 'liberalism' so far as to include Nazism $^{8}$ or bracket out Nazi biopolitics as an inexplicable exception to the rule. Both solutions are theoretically unsatisfactory. The problem arises, I suggest, from the equation of modern economic rationality with liberalism. Once we shift the focus from liberal government to the modern logic of increasing and improving human productivity, non-liberal or even anti-liberal totalitarian biopolitics is no longer a contradiction in terms.

Note that, for Nazi biopolitics, the master race was not an existing entity, nor was it co-extensive with the German nation; the master race was something to be actively created, and improving its life was a concerted, future- 
oriented effort to be executed through policies that included selective family allowances as well as forcible sterilization and organized mass murder. All these measures were designed to improve the strength, health, and purity of the coming master race. Anyone who would not conform to this vision constituted a threat or a burden that needed to be eliminated. Hence, taking life was a means of making life; destroying life in the present was a means of optimizing life in the future. Death

now presents itself as the counterpart of a power that exerts a positive influence on life, that endeavours to administer, optimize, and multiply it, subjecting it to precise controls and comprehensive regulations. (Foucault 1980, 137)

Like capital, biopolitics in its extreme form maximizes life on the supra-individual level by turning the living into the dead. Conversely, capital in Marx assumes a life-like, self-sustaining, proliferating form of life through feeding upon living labor and turning it into dead labor.

\subsection{The Time of Capital and Biopolitics}

Temporality figures prominently in Marx and Foucault. To summarize the foregoing, the significance of temporality concerns three major aspects: an emphasis on the historicity of the present, an ontology of performance, and the diagnosis of a particular temporal dynamics which I will term 'the dynamics of end-less progression'. Let us recapitulate these three aspects of temporality:

Historicity: The point of critique for Marx and Foucault is to expose the fundamentally historical, contingent status of the prevailing forms of social thought and practice in the present. ${ }^{9}$ They deploy historical analysis as a way to undermine the belief in alleged universals and render contestable the mechanisms that create the appearance of ahistorical universality and immutability. Critique, understood thus, may enable contemporaries to contest

For Foucault's model of critique in comparison to that of Horkheimer and Adorno, see Vogelmann 2018. Much of what Vogelmann states about the inherent nexus of diagnosis, critique and social change in Horkheimer and Adorno, I would add, in fact hearkens back to Marx. 
these mechanisms and ultimately replace them with more emancipatory practices and social relations. Neither value nor wage labor, nor the resulting form of wealth as an accumulation of commodities, is a timeless universal; on the contrary, these are rather recent ways of organizing social life. The same can be said for the notion of life and the imperative to enhance it, the notion of sexuality and the imperative to liberate it, the notion of the population and the imperative to improve it. Realizing the fundamentally contingent character of such alleged universals, according to Marx and Foucault, may enable us to conceive of things differently and ultimately do things differently. Wealth, for instance, must not necessarily take the form of an accumulation of commodities. This is in truth a poor, reductive and destructive form of wealth. We should replace it with a different, a more sustainable, a more just and inclusive one that acknowledges and values nature and human faculties as its sources. Rather than an accumulation of commodities, we could, for instance, consider solidarity to be the form of wealth we want to achieve.

Ontology of performance: Foucault states explicitly that power "is something that is exercized and that it exists only in action" $(2003,14)$. Power is neither an entity nor an instrument or structure; thus, it is never static or fixed. In order to exist, it must be actively performed. Similarly, Marx conceives of value as existing only in action. Value must be realized, and it can be realized only through the act of exchange; if this does not take place, value does not exist. Moreover, all of the major forms analyzed by Marx turn out to be the prevailing way of doing something: commodity, exchange value, value, money, and wage labor are all historically specific forms of organizing social life. They exist only in action: commodities, value, and wage labor must all be produced, exchanged, realized, valorized, reproduced, or accumulated in order to be what they are. This means, in turn, that they will cease to exist when we invent other ways of organizing social life.

End-less progression: Capital and biopolitics share a temporal structure that can be described as the dynamics of end-less progression. The mode of existence of both capital and biopolitics, as shown above, is that of an ongoing process that is simultaneously endless and directed: Capital accumulation and biopolitics are end-less in that they have no attainable ends and no conceivable end-point. Yet they are directed, namely towards maximization and optimization: an increased accumulation of value and an optimized functionality of life. In addition, it can be said that both capital accumulation for Marx and biopolitics for Foucault proceed through using and increasing the productive forces of life: The valorization of value includes the use of living labor, 
the production of surplus value, the realization of surplus value on the market-and, in the interest of sustaining one's economic existence, investing at least part of the surplus value to further increase the productive forces of living labor through deploying more efficient technology. Thus, exploiting life in the form of living labor and constantly increasing its productivity ultimately form two facets of the same historically unprecedented dynamic. Again, we see the resemblance between capital in Marx and biopolitics and biopower in Foucault, both allowing the extraction the forces of life at the same time as their increase, optimization and maximization.

Above, I argued that the concept of biopolitics captures a specifically modern way of integrating the individual and the social whole- - "omnes et singulatim", all and one-as Foucault put it (1994a). Biopolitics, in this sense, provides a set of social and political technologies that supposedly benefit the individual and the social order at the same time. Yet this promise relies on the underlying temporal structure of end-less progress. After all, it is only the presupposition of constant, irreversible and inexorable progress towards the better that may render at least some credibility to the abovementioned promise, allowing for the constant deferring of its fulfilment into the future. ${ }^{10}$ In fact, the present constantly fails to deliver, and a harmonious integration of all and one is nowhere in sight. Against this continuous experience, the promises of modernity, capitalism, and biopolitics rely on the stipulation of progress. Progress will bring increased productivity, which will bring improved living conditions, which will bring increased productivity and so forth. Modernity, in short, relies on the-joint and constant-improvement of life and productivity in time, or at least the promise thereof. Marx and Foucault expose this nexus, which is why they shift our attention from repression to productivity and towards a new type of power that constantly seeks to optimize the functionality and the productive forces of life. The problem is that optimizing the forces of life coincides with reproducing social relations of exploitation and subjugation as well as norms and standards of functionality, usefulness, productivity and fitness. The counterpart of enhancing life is the devaluation of those who do not meet these standards or are deemed not to meet them. Thus, the imperative of optimizing life fuels the notion of life that is not good enough, that does not meet the standards of fitness and functionality, that

10 Again, I thank Peter Wehling for making this point and for reminding me of Walter Benjamin's critique of the idea of irreversible, inexorable progress in empty, homogenous time (Benjamin 1980, 258). 
is not strong, healthy, useful, fit or happy enough. Optimizing life implies the construction, problematization, and devaluation of 'deficient life', a construction which, in turn, fuels the demand for technoscientific investments to 'solve' these 'problems' and optimize life further.

\subsection{Conclusion}

What, then, can be learnt about the relationship between biopower and capitalism from revisiting Marx and Foucault? How can we capture it by re-reading one in light of the other? In any case, this reading does not support a deterministic conception according to which capitalism could have caused biopower and biopolitics or vice versa. It also does not support a functionalist conception indicating that biopower and biopolitics have emerged because they perform certain necessary functions for capitalism or vice versa. Neither of these constructions can be historically or theoretically substantiated, at least not on the basis of Marx or Foucault. On the other hand, stating a mere coincidence, a random overlap of two unrelated phenomena, would also fail to harness the theoretical potential of such a reading. Rather, I suggest, we can discern a common core of biopower and capitalism, a certain logic that they share but that distinguishes them sharply from previous modes of production and types of power, respectively. The key to understanding this logic, I suggest, is a new and distinct connection of power and temporality that was brought about by modernity and is characterized by the co-constitution of productive power and a future-oriented, yet end-less movement that I have termed the dynamics of end-less progression. What distinguishes productive power from repressive, extractive, banning types of power is essentially its capacity to turn human life into a resource that can be used and harnessed and increased at the same time. This is what biopower and capital do: they simultaneously harness and increase the forces of human life. This does not mean that the forces of life need be understood in a bio-realist or vitalist way, as an independent, ahistorical reality. It is the converse: life is that which can be simultaneously harnessed and increased. As such, it is a fundamentally historical phenomenon and contingent on productive power.

In short, productive power is the type of power geared at increasing the functionality, productivity, efficiency and performance of human life, that is, at increasing the production of productivity. Yet to avoid misunderstandings, it must also be stated that productive power does not necessarily improve or 
prolong the lives of individuals, nor does it necessarily harness the potential of any individual. Using, wasting, damaging or even discarding the life of individuals is not incompatible with the logic of capital and biopower-in principle or in practice. At the macro-level, the level of the population, of society, of the master race, or of whatever collectivity is constructed as a reference, the forces of life may well be increased and optimized regardless of the damage done to individual lives. This constitutes a certain tension, however, within the logic of productive power. On the one hand, it is the claim and the promise of modern biopower and capitalism alike to serve the benefit of "omnes et singulatim" at once. Increasing productivity, functionality and efficiency at the macro-level will automatically benefit the lives of the individuals, and, conversely, increasing the productivity, functionality and efficiency of individuals will benefit society at large. On the other hand, the epoch of biopower and capitalism did not put an end to misery, poverty, insecurity and suffering, at least not for all and not for long; the claim of improving life for each and all is constantly refuted by lived experience. Hence the necessity of constant progression: If life has not yet improved for each and all, it is because we have not done enough to improve the forces of life, to increase the production of productivity. We must increase, improve, optimize, and possibly accelerate them further. We must comply with the imperative of constant improvement. With Marx, we can see the absurdity of this logic; it is not only that producing productivity also produces misery and exploitation, but that feeding the process also becomes an end in itself. Living labor becomes a means of propelling productivity instead of productivity becoming a means of serving human needs. Moreover, within the confines of this logic, there is no room to ask which needs productivity should actually serve and at what cost, and what kind of society with which mode of production would be needed to achieve these ends. With Foucault, in turn, we can see that improving life operates as a norm, and a norm implies the existence of the abnormal. Thus, improving life also entails producing deficient life, life that does not meet the standards, that is not productive, not functional, not fit enough. The imperative of improving life thus implies the degradation of human lives considered deficient, abnormal, unworthy according to norms and standards that are never stable-because there is always room for improvement. 
